\title{
DESEMPENHO PRODUTIVO DE QUATRO GRUPOS GENÉTICOS DE CODORNAS (Coturnix sp.) PARA CORTE
}

\section{(Growth performance evaluation of four genetic groups of meat quails, Coturnix sp.)}

\author{
OLIVEIRA, E.G. ${ }^{1}$; ALMEIDA, M.I.M²; MENDES, A.A. ${ }^{3}$; VEIGA, N. ${ }^{3}$; DIAS, K. ${ }^{4}$ \\ 1'Deptํㅡㄴootecnia, SCA, UFPR, Curitiba ego@ufpr.br; \\ ${ }^{2}$ Dept ํ Genética, SCB, UFPR, Curitiba; \\ ${ }^{3}$ Depto ${ }^{0}$ Produção e Exploração Animal, FMVZ, UNESP, Botucatu; \\ ${ }^{4}$ Doutoranda em Genética UNESP, Araçatuba.
}

\begin{abstract}
RESUMO - Para avaliar o desempenho produtivo, o rendimento de carcaça e a melhor idade de abate de quatro grupos genéticos de codornas machos e fêmeas para corte, criadas de 1 a 77 dias e abatidas semanalmente de 35 a 77 dias, utilizaram-se 1984 aves, distribuídas aleatoriamente em um delineamento inteiramente casualizado, com esquema fatorial de 2 sexos $\times 4$ famílias ( $A, B, C$ e $D)$, num total de 8 tratamentos com 4 repetições de 62 aves cada. A partir dos 28 dias as fêmeas foram mais pesadas do que os machos, independentemente da família. A família $A$ foi mais pesada do que a B aos 35, 56 e 77 dias. A partir dos 42 dias, as fêmeas tiveram maior consumo, mas melhor conversão alimentar do que os machos. Considerando-se conjuntamente os dados de desempenho, a melhor idade de abate para ambos os sexos foi 49 dias.
\end{abstract}

Palavras-chave: codorna de corte, desempenho, idade de abate, linhagem, rendimento.

ABSTRACT - A trial was conducted with the objective to evaluate growth performance, carcass yield, and slaughtering age of four genetic groups of meat quail, of both sexes, raised from 1 to 77 days and slaughtered weekly from 35 to 77 days. The experiment utilized 1984 birds, in a completely randomised design, with a factorial of 2 genders and 4 families (A, B, C and D), in a total of 8 treatments with 4 replicates of 62 birds each. Body weight of female quail at 28 days was higher than other ages independently of family. Family $A$ was heavier than family $B$ at 35,56 and 77 days. At 42 days of age female showed higher feed consumption and low feed conversion than male. Considering the results as a whole, the best slaughtering age for both genders was 49 days. Key-words: genetic group, growing performance, meat quail, production, slaughtering age.

\section{Introdução}

A coturnicultura é responsável por uma considerável faixa do mercado avícola mundial, havendo grande aceitabilidade dos seus produtos (PANDA e SINGH, 1990; BAUMGARTNER, 1994). Porém existem poucas informações disponíveis sobre as características zootécnicas destas aves nas condições de produção nacionais.

As codornas para corte apresentam uma taxa de crescimento e um peso final muito maiores do que as de postura, o que permite que cheguem a um peso adequado ao abate numa idade bastante precoce. Um dos fatores que contribui para este crescimento mais rápido é o maior consumo de alimento nos primeiros estágios de vida descrito por MARKS (1991), que observou que a correlação entre velocidade de crescimento e consumo de ração é alta em várias aves domésticas, entre elas frangos e codornas de corte.

Diversos autores constataram diferenças de peso entre linhagens de codornas selecionadas para corte (CARON et al., 1990; MARKS, 1993a; OGUZ et al., 1996), tendo sido observadas variações de um mínimo de 113,4g (BAUMGARTNER et al., 1985) até $217,0 \mathrm{~g}$ (CAMPION et al., 1982) aos 56 dias de idade. Também a conversão e a eficiência alimentares e o ganho de peso são significativamente afetados pela linhagem ou variedade das aves (MARKS, 1991; 1993a; MICHALSKA e KORZYNSKA-NOVAK, 1992).

O trabalho de CARON et al. (1990) mostrou que as fêmeas são mais pesadas do que os machos de mesma idade. OGUZ et al. (1996) não observaram efeito de sexo em nenhuma idade de 1 a 42 dias, mas a linhagem com a qual trabalharam foi obtida por seleção massal às 4 semanas, usando-se uma intensidade de seleção maior para machos (10\%) do que para fêmeas (30\%).

O presente estudo teve como objetivo específico avaliar o desempenho produtivo de quatro grupos genéticos de codornas (Coturnix sp.) para corte, de ambos os sexos, criadas de 1 a 77 dias de idade.

\section{Material e Métodos}

Foram utilizadas 1984 codornas comerciais para corte, sendo 496 de cada um de quatro grupos genéticos, designados por famílias $A, B, C$ e $D$, na proporção de $50 \%$ de cada sexo. As aves de um dia foram sorteadas aleatoriamente em um delineamento inteiramente casualizado, em esquema fatorial de 2 sexos $\times 4$ famílias, dando um total de 8 tratamentos, com 4 repetições de 62 aves cada.

O experimento foi realizado nas instalações da 
UNESP- Botucatu. As aves foram alojadas em galpão semifechado, em boxes medindo $1,00 \mathrm{~m}$ de largura $\mathrm{x}$ $1,00 \mathrm{~m}$ de comprimento $\times 1,20 \mathrm{~m}$ de altura, providos com cama de maravalha de madeira. Cada box foi equipado com uma campânula elétrica, bebedouro e comedouro. Os animais foram alimentados à vontade durante todo 0 período com uma ração única, farelada, isocálcica e isofosfórica, com $24 \%$ de proteína bruta e $2900 \mathrm{kcal}$ de energia metabolizável, baseada nas recomendações do NRC (1994) para codornas em fase de crescimento.

O desempenho das aves foi avaliado através do controle da mortalidade, do peso, do ganho de peso, do consumo de ração e da conversão alimentar [CA =
Consumo de ração / (Ganho de peso + Peso de mortos].

Os dados foram submetidos a análise de variância pelo procedimento GLM do programa SAS (1989).

\section{Resultados e Discussão}

Não foi observada interação entre sexo e família em nenhuma variável. O grupo genético (família) não exerceu influência sobre o peso médio até aos 49 dias de idade, porém a partir dos 56 a família A apresentou médias maiores do que a $B(p<0,05)$, diferença que se acentuou até aos 77 dias (FIGURA 1). Não houve diferença entre as demais famílias.

FIGURA 1 - PESO MÉDIO DE CODORNAS DE CORTE DE QUATRO FAMÍLIAS DE 1 A 77 DIAS DE IDADE.

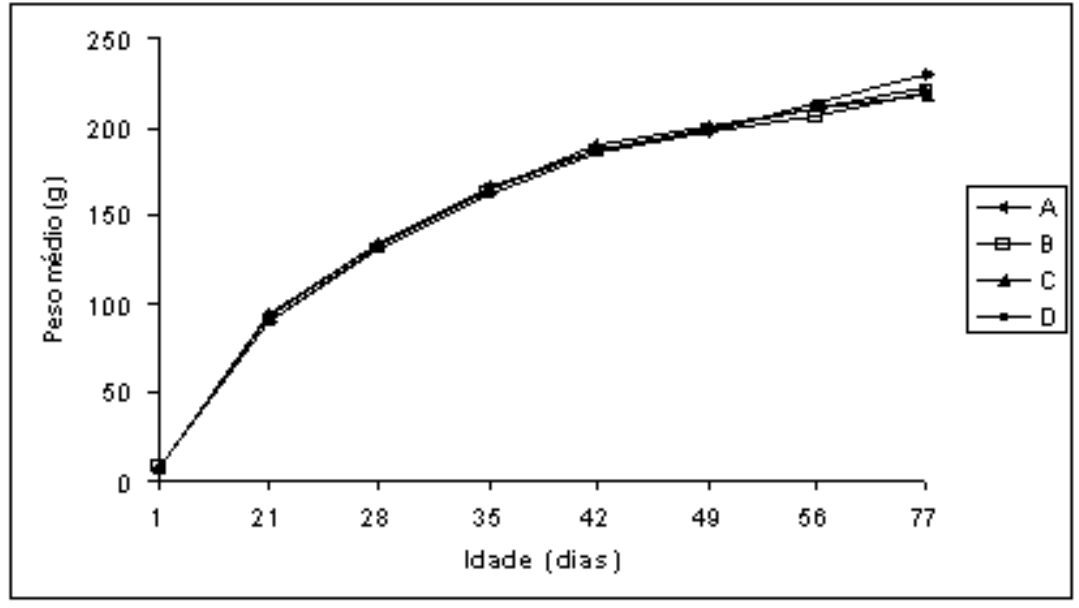

As médias de peso final e de ganho de peso estão de acordo com as informações da literatura internacional para a mesma faixa etária para linhagens selecionadas longamente para corte (MARKS, 1993b), sendo superiores às relatadas para linhagens que sofreram seleção para alto peso por cinco gerações ou menos (OGUZ et al., 1996). Os efeitos de linhagem ou grupo genético sobre características de peso são bem documentados mesmo entre aves de mesmo tipo (CARON et al., 1990; MARKS, 1993a; OGUZ et al., 1996).

As fêmeas apresentaram superioridade de ganho de peso médio e de peso médio a partir dos 28 dias, adquirindo significância $(\mathrm{p}<0,05)$. A diferença acentuou-se até ao final do período experimental, aos 77 dias (FIGURA 2 e TABELA 1).

FIGURA 2 - PESO MÉDIO DE CODORNAS DE CORTE MACHOS E FÊMEAS DE 1 A 77 DIAS DE IDADE.

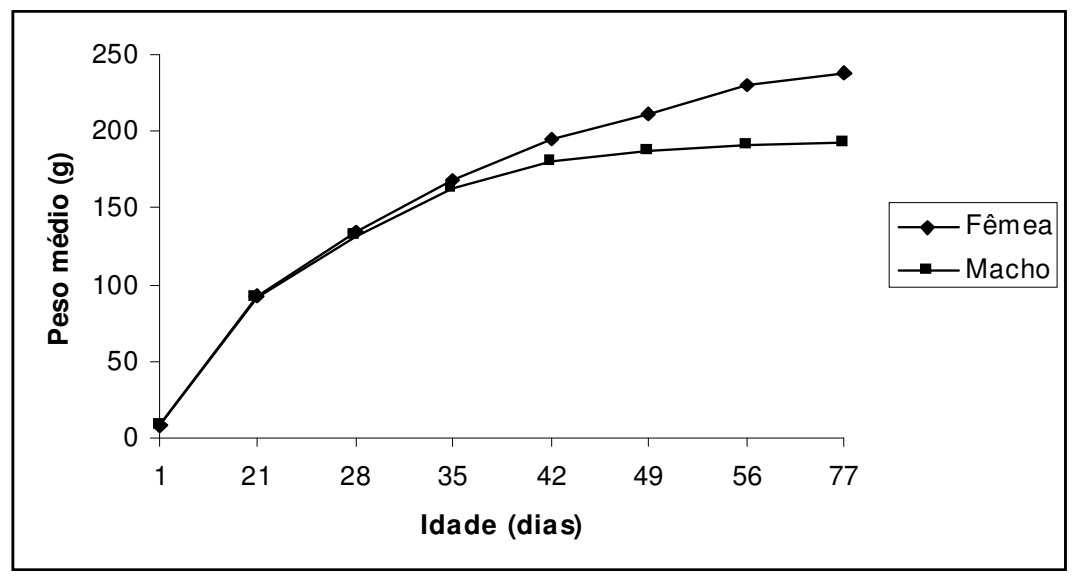


Presumia-se isso, uma vez que é conhecido o dimorfismo sexual nas codornas domésticas (TOELLE et al., 1991) que faz com que as fêmeas sejam de 5 a $20 \%$ mais pesadas do que os machos de mesma idade, dependendo das linhagens e idades comparadas (MINVIELLE et al., 1999). Esta diferença surge entre 21 e 28 dias, com a proximidade da maturidade sexual, que ocorre por volta dos 42 dias de vida, e acentua-se até à idade adulta, sendo devida, principalmente, ao maior peso do fígado e trato reprodutivo das fêmeas (OGUZ et al., 1996). O crescimento dos machos cessou em torno dos 42 dias. As fêmeas aumentaram de peso após a maturidade sexual, similarmente ao relatado por BACON e NESTOR (1983) no estudo realizado com fêmeas adultas de codornas selecionadas para alto peso. Os autores ressaltaram que este aumento é devido principalmente à deposição de gordura.

TABELA 1 - GANHO DE PESO MÉDIO DE CODORNAS DE CORTE DE QUATRO FAMÍLIAS E AMBOS OS SEXOS, AVALIADAS POR PERÍODO DE 1 A 77 DIAS DE IDADE.

\begin{tabular}{ccc}
\hline Período (dias) & Fêmea & Macho \\
\hline 1 a 21 & 84,5 & 83,7 \\
1 a 28 & $1270^{\mathrm{a}}$ & $123,6^{\mathrm{b}}$ \\
1 a 35 & $160,3^{\mathrm{a}}$ & $154,4^{\mathrm{b}}$ \\
1 a 42 & $186,7^{\mathrm{a}}$ & $172,8^{\mathrm{b}}$ \\
1 a 49 & $202,5^{\mathrm{a}}$ & $179,7^{\mathrm{b}}$ \\
1 a 56 & $221,8^{\mathrm{a}}$ & $183,4^{\mathrm{b}}$ \\
1 a 77 & $238,0^{\mathrm{a}}$ & $192,2^{\mathrm{b}}$ \\
\hline
\end{tabular}

Letras minúsculas diferentes na mesma linha indicam diferenças significativas $(p<0,05)$ entre as médias de sexo.

O efeito de sexo influenciou o consumo médio de ração em todas as fases a partir do período de 1 a 42 dias (TABELA 2); a conversão alimentar das aves sofreu este efeito nos mesmos períodos à exceção do último, de 1 a 77 dias (TABELA 3).

TABELA 2 - CONSUMO MÉDIO DE RAÇÃO DE CODORNAS DE CORTE DE QUATRO FAMÍLIAS E AMBOS OS SEXOS, AVALIADAS POR PERÍODO DE 1 A 77 DIAS DE IDADE.

\begin{tabular}{ccc}
\hline Perío do (dias) & Fêmea & Macho \\
\hline 1 a 21 & 2095 & 211,2 \\
1 a 28 & 347,7 & 346,2 \\
1 a 35 & 503,7 & 499,4 \\
1 a 42 & $680,6^{\mathrm{a}}$ & $6635^{\mathrm{b}}$ \\
1 a 49 & $860,2^{\mathrm{a}}$ & $813,5^{\mathrm{b}}$ \\
1 a 56 & $1061,3^{\mathrm{a}}$ & $961,3^{\mathrm{b}}$ \\
1 a 77 & $1727,4^{\mathrm{a}}$ & $1379,1^{\mathrm{b}}$ \\
\hline
\end{tabular}

Letras minúsculas diferentes na mesma linha indicam diferenças significativas $(p<0,05)$ entre as médias de sexo.

TABELA 3 - CONVERSÃO ALIMENTAR MÉDIA DE CODORNAS DE CORTE DE QUATRO FAMÍLIAS E AMBOS OS SEXOS, AVALIADAS POR PERÍODO DE 1 A 77 DIAS DE IDADE.

\begin{tabular}{ccc}
\hline Perío do (dias) & Fêmea & Macho \\
\hline 1 a 21 & 2,481 & 2,524 \\
1 a 28 & 2,738 & 2,802 \\
1 a 35 & 3,14 & 3,233 \\
1 a 42 & $3,645^{\text {a }}$ & $3,840^{\mathrm{b}}$ \\
1 a 49 & $4,248^{\mathrm{a}}$ & $4,529^{\mathrm{b}}$ \\
1 a 56 & $4,784^{\mathrm{a}}$ & $5,246^{\mathrm{b}}$ \\
1 a 77 & 7,3 & 7,2 \\
\hline
\end{tabular}

Letras minúsculas diferentes na mesma linha indicam diferenças significativas $(p<0,05)$ entre as médias de sexo.

Pode-se observar que, embora as fêmeas tenham tido um consumo maior do que o dos machos, a sua conversão foi melhor o que pode ser explicado pela maior taxa de crescimento (TABELA 1). Até aos 35 dias o efeito de sexo não foi significativo $(p>0,05)$ sobre nenhuma destas características, aparecendo apenas a partir dos 42 dias, idade em que ocorre a maturidade sexual. Este fenômeno fisiológico tem efeitos totalmente diversos sobre cada um dos sexos. Enquanto as fêmeas se preparam para a postura, alimentando-se mais para compensar o desgaste representado pela produção diária de um ovo (em codornas, mesmo nas linhagens 
de corte, não é rara a postura de até dois ovos por dia, como citam TABOADA et al., 1998), os machos desenvolvem um comportamento competitivo, para determinar os padrões de dominância social. Ainda que não haja fêmeas presentes, os machos competem entre si por território, alimento e água, de forma extremamente violenta. No presente experimento foi comum a retirada de machos mortos em estado de completa caquexia e muito mutilados, principalmente entre os 42 e os 56 dias de idade, fase em que se estabeleceram as relações de dominância e submissão dentro de cada box experimental.

Nem o consumo médio nem a conversão alimentar sofreram efeito de família. Independentemente da família ou sexo considerado a conversão alimentar piorou com a idade, aumentando consideravelmente quando se analisaram períodos acima dos 49 dias. Resultados semelhantes foram encontrados por SHRIVASTAV e PANDA (1991).

Nas condições em que este trabalho foi realizado, a mortalidade foi uma variável difícil de interpretar. Os coeficientes de variação extremamente altos obtidos em todos os períodos analisados, motivados por uma variação muito grande dentro dos próprios tratamentos, tornou impossível a detecção de significância estatística para as diferenças de médias apresentadas na TABELA 4.

TABELA 4 - MORTALIDADE MÉDIA DE CODORNAS DE CORTE DE QUATRO FAMÍLIAS E AMBOS OS SEXOS, AVALIADAS POR PERÍODO DE 1 A 77 DIAS DE IDADE.

\begin{tabular}{ccc}
\hline Período (dias) & Fêmea & Macho \\
\hline 1 a 21 & 3,9 & 3 \\
1 a 28 & 4,1 & 32 \\
1 a 35 & 4,6 & 3,4 \\
1 a 42 & 4,8 & 35 \\
1 a 49 & 4,8 & 4,3 \\
1 a 56 & 5 & 6,1 \\
1 a 77 & 8,6 & 11,4 \\
\hline
\end{tabular}

Isto indica que os fatores considerados como principais neste experimento (sexo e família), não foram os principais responsáveis pela incidência de mortalidade em codornas de corte de 1 a 77 dias de idade. Contudo, embora não tenha sido possível detectar significância para o efeito de sexo $(p>0,05)$, pode-se observar uma diferença de comportamento para a mortalidade entre os machos e as fêmeas. Nos primeiros períodos as médias de mortalidade de machos e fêmeas foram bastante semelhantes, com as fêmeas apresentando valores ligeiramente superiores Contudo, comparando-se os períodos 1 a 42 e 1 a 49 dias notase que a mortalidade dos machos aumentou mais do que a das fêmeas, diferença esta que se acentuou nos períodos subsequentes, indicando que a partir dos 42 dias começou a ocorrer uma maior mortalidade de machos. A principal causa desta diferença de comportamento da variável foi a maturidade sexual, e os conseqüentes confrontos agonísticos muito violentos entre os machos.

\section{Conclusões}

Diante dos resultados encontrados pode-se concluir que as codornas introduzidas no Brasil com o objetivo de produção de carne apresentam excelente aptidão para esta finalidade, independentemente de grupo genético, apresentando bom ganho de peso e peso final até aos 49 dias de idade. O aumento da conversão alimentar em ambos os sexos, da mortalidade dos machos decorrente da competição pela hierarquia de dominância sexual, e o início da postura tornam desinteressante a manutenção das aves após esta idade.

Archives of Veterinary Science, v.10, n.3, p.33-37, 2005

\section{Referências}

BACON, W.L.; NESTOR, K.E. Divergent selection for body weight and yolk precursor in Coturnix coturnix japonica. 5 . Correlated responses in adult body weight, liver weight, ovarian follicle production and carcass composition of laying hens. Poultry Science, Champaign, v.62, p. 1876 - 1884, 1983.

BAUMGARTNER, J. Japanese quail production, breeding and genetics. World Poultry Science Journal. Ithaca, v. 50 n. 3 p. 227 - 235, 1994.

BAUMGARTNER, J.; KOCIOVA, E.; POLANSKA, O. Carcass and nutritive value of japanese quail. Roczniki Naukowe Zootechniki, v.12, n.1, p.171-178, 1985.

CAMPION, D.R.; MARKS, H.L.; REAGAN, J.O.; BARRET, J.B. Composition and muscle cellularity of japanese quail after selection for high body weight under an optimal or suboptimal nutritional environment. Poultry Science. Champaign, v.61, p. 212-217, 1982.

CARON, N.; MINVIELLE, F.; DESMARAIS, M.; POSTE, L.M. Mass selection for 45-day body weight in japanese quailp. selection response, carcass composition, cooking properties, and sensory characteristics. Poultry Science. Champaign, v.69 n.7, p.1037-1045, 1990.

MARKS, H.L. Feed efficiency changes accompanying selection for body weight in chikens and quail. World's Poultry Science Journal. Ithaca, v.47, p.197-212, 1991.

MARKS, H.L. Carcass composition, feed intake, and feed efficiency following long-term selection for four-week body weight in japanese quail, Poultry Science. Champaign, v.72, n.6, p.1005-1011, 1993a. 
MARKS, H.L. The influence of dietary protein level on body weight of japanese quail lines selected under high- and low-protein diets. Poultry Science. Champaign, v.72, n.6, p.1012-1017, 1993b.

MICHALSKA, E.; KORZYNSKA-NOWAK, R. Growth of japanese quail in relation to generation, parentage and sex. Prace i Materialy Zootechniczne, n.42, p.91-101, 1992.

MINVIELLE, F.; HIRIGOYEN, E.; BOULAY, M. Associated effects of the roux plumage color mutation on growth, carcass traits, egg production and reproduction of japanese quail. Poultry Science. Champaign, v.78, p.1479-1484, 1999.

NATIONAL RESEARCH COUNCIL (NRC) $7^{\underline{a}}$ ed. Washington, National Academy Press, 1994.

OGUZ, I.; ALTAN, O.; KIRKPINAR, F.; SETTAR, P. Body weights, carcass characteristics, organ weights, abdominal fat and lipid content of liver and carcass on two lines of japanese quail (Coturnix coturnix japonica), unselected and selected for four week body weight. British Poultry Science. Essex, v. 37, p.579-588, 1996.
PANDA, B.; SINGH, R.P. Developments in processing quail meat an eggs. World's Poultry Science Journal. Ithaca, v.46 n.11, p.219-234, 1990.

STATISTICAL ANALYSIS SYSTEM (SAS). Languages and procedures. Version 6. Cary: SAS Institute, 1989, $638 \mathrm{p}$.

SHRIVASTAV, A. K.; PANDA, B. Distribuition of fat at different locations as influenced by dietary caloryprotein ratio and energy levels in quail broilers. Indian Veterinary Medical Journal. New Delhi, v.15, n.3, p.178184, 1991.

TABOADA, P.; PEREZ, A.; MYRA, J.; MORFA, O.; SANCHEZ, M.E. Efectos del sexo sobre los rendimientos en la codorniz japonesa (Coturnix coturnix japonica) y la composición química de su carne. Rev. Cubana de Ciencia Avícola. n.22 p.19-24, 1998.

TOELLE, V.D.; HAVENSTEIN, G.B.; NESTOR, K.E.; HARVEY, W.R. Genetic and phenotipic relationships in japanese quail. 1. Body weight, carcass and organ measurements. Poultry Science. Champaign, v.70, p. 1679-1688, 1991.

Recebido para publicação: 05/11/2005

Aprovado: $\quad$ 15/02/2006 